\title{
Nutritional Factors That Influence Change in Bone Density and Stress Fracture Risk Among Young Female Cross-Country Runners
}

\author{
Jeri W. Nieves, PhD, Kathryn Melsop, MS, Meredith Curtis, BS, \\ Jennifer L. Kelsey, PhD, Laura K. Bachrach, MD, Gail Greendale, MD, \\ Mary Fran Sowers, PhD, Kristin L. Sainani, PhD
}

Objective: To identify nutrients, foods, and dietary patterns associated with stress fracture risk and changes in bone density among young female distance runners.

Design and Setting: Two-year, prospective cohort study. Observational data were collected in the course of a multicenter randomized trial of the effect of oral contraceptives on bone health.

Participants: One hundred and twenty-five female competitive distance runners ages 18-26 years.

Assessment of Risk Factors: Dietary variables were assessed with a food frequency questionnaire.

Main Outcome Measurements: Bone mineral density and content (BMD/BMC) of the spine, hip, and total body were measured annually by dual x-ray absorptiometry (DEXA). Stress fractures were recorded on monthly calendars, and had to be confirmed by radiograph, bone scan, or magnetic resonance imaging.

Results: Seventeen participants had at least one stress fracture during follow-up. Higher intakes of calcium, skim milk, and dairy products were associated with lower rates of stress fracture. Each additional cup of skim milk consumed per day was associated with a $62 \%$ reduction in stress fracture incidence $(P<.05)$; and a dietary pattern of high dairy and low fat intake was associated with a $68 \%$ reduction $(P<.05)$. Higher intakes of skim milk, dairy foods, calcium, animal protein, and potassium were associated with significant $(P<.05)$ gains in whole-body BMD and BMC. Higher intakes of calcium, vitamin D, skim milk, dairy foods, potassium, and a dietary pattern of high dairy and low fat were associated with significant gains in hip BMD.

Conclusions: In young female runners, low-fat dairy products and the major nutrients in milk (calcium, vitamin D, and protein) were associated with greater bone gains and a lower stress fracture rate. Potassium intake was also associated with greater gains in hip and whole-body BMD.

PM R 2010;2:740-750

\section{INTRODUCTION}

Stress fractures are common among young female competitive athletes, especially among those participating in track and field, for whom the 1-year incidence rates have ranged from $8.7 \%$ to $21.1 \%[1,2]$. Studies evaluating the impact of dietary factors on stress fracture incidence in female athletes are limited and inconsistent. Some, but not all, studies have found that disordered eating [3,4], low calcium and dairy product intake [5], and low dietary fat intake [3] may be related to stress fractures in female athletes. Only one of these prior studies was prospective [3], and most are based on small numbers of study subjects and did not adequately control for confounding variables in the statistical analysis. Observational studies in female military recruits have not found a relationship between calcium intake [6] or dairy consumption (asked as a crude yes/no question) [7] and stress fracture risk, but a recent randomized trial found that calcium supplementation prevents stress fractures in this population [8].

J.W.N. Clinical Research Center, Helen Hayes Hospital, Route 9W, West Haverstraw, NY 10993; Columbia University, New York, NY. Address correspondence to: J.W.N.; e-mail: jwn5@columbia.edu

Disclosure: nothing to disclose

K.M. Division of Epidemiology, Department of Health Research and Policy, Stanford University School of Medicine, Stanford, CA Disclosure: nothing to disclose

M.C. Division of Epidemiology, Department of Health Research and Policy, Stanford University School of Medicine, Stanford, CA Disclosure: nothing to disclose

J.L.K. Division of Epidemiology, Department of Health Research and Policy, Stanford University School of Medicine, Stanford, CA; Division of Preventive and Behavioral Medicine, University of Massachusetts Medical School, Worcester, MA

Disclosure: nothing to disclose

L.K.B. Department of Pediatrics, Stanford University School of Medicine, Stanford, CA Disclosure: nothing to disclose

G.G. Geffen School of Medicine at UCLA, Los Angeles, CA

Disclosure: nothing to disclose

M.F.S. Department of Epidemiology, School of Public Health, University of Michigan, Ann Arbor, MI

Disclosure: nothing to disclose

K.L.S. Division of Epidemiology, Department of Health Research and Policy, Stanford University School of Medicine, Stanford, CA Disclosure: nothing to disclose

Disclosure Key can be found on the Table of Contents and at www.pmrjournal.org

This study was funded by a grant from the U.S Army Medical Research and Materiel Command, award number DAMD17-98-1-8518. Wyeth-Ayerst provided oral contraceptives for the randomized trial from which these data are derived, but was not involved in the analyses presented in this article.

Submitted for publication December 18, 2009; accepted April 22, 2010. 
Female endurance athletes are at risk for compromised peak bone mass [9], which might be an important risk factor for osteoporosis later in life [10]. The relationship between disordered eating, insufficient caloric intake, and low bone density is well established in this population [9]. However, the relationships between specific nutrients and foods and bone density are less well understood. Prior studies that examined the association between specific dietary components and bone mineral density (BMD) in female athletes were cross-sectional or retrospective [11-13]. No published studies have examined these relationships prospectively in this population.

In contrast, the role of diet in the development of peak bone mass has been well studied in the general population. There is good evidence that calcium, vitamin $\mathrm{D}$, and protein help promote bone growth in children, teens, and young adults [14-26,33]. Diets high in fruits and vegetables have also been associated with higher BMD in several studies [27-32]. Iron status may relate to bone loss in older women $[34,35]$, but this has not been studied in younger women. High milk intake has been correlated with greater $\mathrm{BMD}$, greater bone acquisition in young adults, and lower risk of fractures later in life [36-40]. Conversely, low milk consumption and high soda consumption may be risk factors for low BMD and adolescent fracture [41,42]. Excessive alcohol intake leads to bone loss [43], whereas moderate alcohol intake may be beneficial to BMD in premenopausal women or have no effect [44]. Coffee has been cited as a contributor to osteoporosis, but moderate intakes (up to 3 cups per day) appear to have no adverse effect on the skeleton in individuals with adequate calcium intake $[45,46]$. Whether these relationships are similar in young female endurance athletes, who have unique risk factors for bone loss and different caloric needs $[47,48]$, is not known.

Several recent studies have noted the importance of considering food groups and dietary patterns of the whole diet on bone health $[37,38,49-51]$. It is possible that any failure to find relationships between single nutrients and bone health may be explained by potential interactions among foods in the diet.

In this article, we use dietary data collected during the course of a randomized trial of the effect of oral contraceptives on bone health to prospectively identify potential nutritional factors and dietary patterns that predict stress fractures and changes in BMD in young female long-distance runners.

\section{METHODS}

\section{Subjects}

Details of the study methodology have been described by Cobb et al [52]. Briefly, 150 runners were recruited from intercollegiate cross-country teams, postcollegiate running clubs, and road race participants. Because of the demands of the randomized trial and the high mobility of this young population, only 125 (83\%) provided follow-up information. Of these, 55 were collegiate runners and 70 were postcollegiate runners. Reasons for withdrawing included: geographic relocation, pregnancy, illness, and lack of time. Baseline characteristics of the participants with no follow-up data were similar to those with follow-up data, except that they were more likely to have a history of stress fracture before baseline $(P=.05)$. At the time of recruitment, most lived near the study sites located in Stanford, CA; Los Angeles, CA; West Haverstraw, NY; Ann Arbor, MI; and Boston, MA. To be eligible, women had to run at least 40 miles per week during peak training times, had to compete in races, could not have used oral contraceptives or other hormonal contraceptives within 6 months of entering the study, had to be willing to be randomized, and to have no contraindications to oral contraceptive use. Eligible women were randomly assigned to receive an oral contraceptive or no intervention for an intended 2 years, stratified according to clinical site. The oral contraceptive pill assigned in this study was Lo/Ovral (Wyeth Ayerst, 28-day pack), which contains $30 \mu \mathrm{g}$ ethinyl estradiol and $0.3 \mathrm{mg}$ norgestrel. For ethical reasons, the athletes and prescribing physicians were not blinded to treatment assignment, and a placebo was not used.

The size of the study population was based on the number needed to provide adequate statistical power for the randomized trial of the impact of oral contraceptive use on bone health, not for the comparisons presented in this article. All procedures followed were in accordance with the ethical standards of the institution or regional committee on human experimentation and the Institutional Review Boards of Stanford University, the University of California Los Angeles, the University of Michigan, the Helen Hayes Hospital, the Massachusetts General Hospital, the U.S. Army Medical Research and Materiel Command, and the colleges at which participants were recruited approved the protocol.

\section{Questionnaire Data}

A self-administered baseline questionnaire was used to obtain information about several variables of interest. Demographic information included age and race/ethnicity. Participants were asked to record their age at menarche and the number of menstrual cycles they had in the previous 12 months. Women were classified as having current menstrual irregularity if they were oligomenorrheic (defined as 4-9 cycles in the past year) or amenorrheic (defined as fewer than 4 cycles in the past year), because recent menstruation is most relevant to current changes in bone mass. Menstrual status was reassessed at each subsequent clinical visit. 


\section{Dietary Assessment}

A modified version of the 97-item National Cancer Institute Health Habits and History food frequency questionnaire [53] was used to estimate usual nutrient intake during the previous 6 months. This was administered at baseline and at each subsequent follow-up visit. We focused on the baseline data in these analyses to preserve the prospective nature of the data with respect to stress fractures. One of the modifications to the questionnaire was the inclusion of additional food items that were likely to be consumed by young athletes and that contained relatively high amounts of calcium. The "fruits and vegetables" and "dairy product" measures used in this article were calculated directly from the food frequency questionnaire by adding the total number of servings of foods considered to be fruits or vegetables to the total number of servings of foods considered to be dairy foods (eg, milk, yogurt, cheese).

A customized automated computer analysis program was used to calculate nutrient intake from the questionnaire. Nutrient variables were adjusted for total energy intake (kcal) by calculating the standardized residual for the following: calcium, vitamin C, vitamin D, phosphorous, potassium, iron, fiber, and fat. Animal and vegetable proteins were calculated as grams per day per kilogram of body weight. Consumption of beverages such as soda, coffee, milk, and alcohol was determined with the food frequency questionnaire; from these responses, total caffeine was determined. Food groups and dietary patterns that represent the combined intake of foods and nutrients were also evaluated.

\section{Physical Measures}

At each of the 5 clinical sites, height and weight were measured using standard stadiometers and balance-beam scales, respectively (Stanford University: Harpenden stadiometer, Mentone Educational, Victoria, Australia/Healthometer scale; University of California Los Angeles: Healthometer; University of Michigan: Healthometer; Helen Hayes Hospital: Measurement Concepts stadiometer/Detecto scale; Massachusetts General Hospital: Healthometer-Healthometer, Jarden Corp., Rye, NY). Body mass index (kilograms per square meter) was calculated from these measurements. Body composition (lean body mass and fat mass) and bone mineral content (BMC) (g) and BMD ( $\mathrm{g}$ per square centimeter) at the left proximal femur, spine, and whole body and were measured by dual energy x-ray absorptiometry (DEXA) (Hologic, Bedford, MA, DXA QDR 4500A at 4 clinical sites, $2000 \mathrm{~W}$ at one site). The coefficient of variation for measuring BMD at the hip and spine in the same person after leaving and then returning to the measuring table on the same day was $2 \%$ or less at each of the clinical sites. For most of the period of data collection, machines were cross-calibrated every 6 months using a circulating Hologic anthropomor- phic spine phantom, and each site maintained a quality assurance program. Participants were asked to return for bone densitometry and measurement of body composition, height, and weight 1 year and 2 years after baseline measurements.

\section{Ascertainment of Stress Fracture Occurrence during Follow-up}

Participants were asked to record the occurrence of a possible stress fracture on a monthly calendar and also to report their occurrence to us immediately. The fracture had to be confirmed by radiograph, bone scan, or magnetic resonance imaging to be counted in this study. All reported stress fractures were confirmed and costs of imaging were assumed by the study where necessary. Participants were also queried periodically about the occurrence of stress fractures by email, phone, and on their questionnaires. No additional stress fractures were reported as a result of these queries.

\section{Statistical Analysis}

Analyses were carried out with the SAS statistical package, version 9.1 (SAS Institute, Cary NC). Baseline nutrient intakes for calcium, vitamin C, vitamin D, phosphorous, potassium, iron, fiber, and fat were adjusted for total caloric intake using the residual method [54]. Units for dairy, fruits, and vegetables are servings per day; units for animal and vegetable protein are grams per day per kilogram of body weight.

Cox proportional hazards models were used to compute adjusted hazard ratios for the relationships between individual dietary factors and stress fracture incidence. Separate models were run for each nutrient, food, or dietary pattern. Hazard ratios were adjusted for clinical assessment site, group to which a participant was randomized, menstrual status at baseline, spine bone density, age, and stress fracture history before enrollment. Though we only present analyses involving the baseline data, we also repeated the analyses modeling nutrients and foods as time-dependent variables (which incorporates follow-up dietary data) and obtained similar results.

We estimated the relationship between specific dietary factors and annual rates of change of BMD and BMC using linear mixed models, adjusted for clinical site, age, annual menses, and treatment assignment in the randomized trial. We tested for confounding by training variables (average distance run in the past year), disordered eating (Eating Disorders Inventory score >69), and changes in body weight, but these variables were not found to have an effect, and therefore were not included in the models presented here.

Dietary patterns were derived from a reduced rank regression method [55], and were evaluated in relation to stress fracture incidence and the rate of change in BMD or BMC. 
Reduced rank regression aims to identify dietary patterns (combination of foods) that are most related to the outcome. In our models, the predictors are foods and the response variables are nutrients that were hypothesized a priori to be important to skeletal health, including calcium, vitamin D, phosphorous, potassium, vitamin $\mathrm{C}$, fiber, fat, and iron. The reduced rank regression identifies those linear functions of the predictors (foods) that explain more of the variance in the response variables (disease-related nutrients) than any other linear functions of foods. These are the dietary patterns that are most likely to relate to stress fractures or annual changes in BMD. Each woman in the dataset gets a score that represents how strongly she follows a given dietary pattern; these scores are then tested for their relationship with stress fracture incidence or longitudinal changes in BMD/BMC. The advantage of this method is that it allows simultaneous evaluation of correlated nutrients because some linear function of all disease-related nutrients may have more discriminating power than any single nutrient.

Effect modifications of the relationship between dietary intake and stress fracture occurrence and change in bone density were evaluated in stratified analyses. All associations of interest were tested for effect modification (statistical interaction) by treatment assignment and menstrual status (eumenorrheic versus oligo/amenorrheic). Several instances of effect modification were found, and are accordingly reported.

\section{RESULTS}

\section{Descriptive Statistics}

Of the 150 subjects originally randomized, one was missing all dietary data; 2 were excluded from analysis because they had reported kilocalorie intakes $>5000$ or $<500$. One subject had diet data but no beverage data, so she is included in the diet analyses but not the beverage analyses. Among the 147 remaining subjects who had baseline diet data (and 146 with baseline beverage data), 125 had follow-up data on stress fracture occurrence and 122 had follow-up BMD measures.

The 125 participants were followed for stress fracture occurrence for a total of 2,792 months, or an average of 1.86 years per woman. Descriptive characteristics of this population are found in Table 1. The average age at baseline was 22 years, $83 \%$ were white, $33.6 \%$ reported menstrual irregularity, and about one third reported a prior stress fracture. Mean BMD of the spine was 0.56 standard deviations below and at the hip was 0.31 standard deviations above the mean for a young normal population, according to Hologic normative data.

The average caloric intake at baseline was 2,280 kcal per day (Table 2). Women in this population had intakes that exceeded the recommended daily intake/recommended daily
Table 1. Selected baseline characteristics $(n=125)$

\begin{tabular}{lc}
\hline \multicolumn{1}{c}{ Characteristic } & $\begin{array}{c}\text { Mean } \pm \mathbf{1} \text { Standard } \\
\text { Deviation or Percentage (n) }\end{array}$ \\
\hline Age (years) & $22.1 \pm 2.6$ \\
Race & $83.2 \%(104)$ \\
White & $4 \%(5)$ \\
Hispanic & $8.8 \%(11)$ \\
Asian/Pacific Islander & $0.8 \%(1)$ \\
Black & $3.2 \%(4)$ \\
Other & $165.9 \pm 6.2$ \\
Height (cm) & $58.5 \pm 6.7$ \\
Weight (kg) & $18.4 \pm 6.1$ \\
Percent body fat & \\
Menstrual category at baseline & $8.0 \%(10)$ \\
Amenorrhea (0-3 periods) & $25.6 \%(32)$ \\
Oligomenorrhea (4-9 & \\
periods) & $66.4 \%(83)$ \\
Eumenorrhea (10+ periods) & $34.5 \pm 11.3$ \\
Weekly miles & $31.2 \%(39)$ \\
Previous stress fractures & \\
Bone density & $0.99 \pm 0.11$ \\
Spine bone mineral density, & \\
g/cm ${ }^{2} / y e a r$ & $0.98 \pm 0.12$ \\
Total hip bone mineral density, & \\
g/cm ${ }^{2} / y e a r$ & $1.11 \pm 0.08$ \\
Whole-body bone mineral & $2173 \pm 294$ \\
density, g/cm ${ }^{2} /$ year & \\
Whole-body bone mineral & \\
content, g/year & \\
\hline
\end{tabular}

allowance for iron, fiber, calcium, vitamin C, and vitamin D. However, intake was lower than recommended for phosphorus and potassium. On average, fruits and vegetables were consumed 5 times per day and dairy (milk, yogurt, or cheese) was consumed about 3 times per day, although only about 8 ounces of milk were consumed per day, and the majority of milk consumed was skim milk (75\%).

\section{Nutrients and Stress Fractures}

Seventeen of the 125 runners had at least one stress fracture, for a rate of 7.3 first stress fractures per 100 person-years of follow-up. Nine of these stress fractures occurred in the tibia, 6 in the foot, and 2 in the femur. Four runners had a second stress fracture: 2 in the tibia, one in the foot, and one in the femur. These second stress fractures are not considered in these analyses.

We found that higher intakes of calcium, skim milk, milk, and servings of dairy products per day were each related to a reduced rate of stress fracture, although the strongest protection was from higher skim milk consumption. Every additional cup of skim milk consumed per day was associated with a $62 \%$ reduced fracture risk $(P<.05)$; every additional serving of dairy products consumed per day conferred a $40 \%$ reduction in risk (Table 3$)(P<.05)$.

The 4 patterns that resulted from the reduced rank regression analysis included: pattern 1: higher consumption of 
Table 2. Descriptive statistics for subjects' baseline selected nutrient and beverage consumption ( $n=125$ )

\begin{tabular}{|c|c|c|c|c|c|}
\hline Nutrient & Mean & $\begin{array}{l}\text { Standard } \\
\text { Deviation }\end{array}$ & Minimum & Maximum & $\begin{array}{c}\text { Dietary Reference Intakes / } \\
\text { Recommended Dietary } \\
\text { Allowance }\end{array}$ \\
\hline Kilocalories/day & 2280 & 913 & 615 & 4664 & \\
\hline Animal protein g/day/kg body weight & 0.86 & 0.51 & 0.11 & 3.2 & \\
\hline Vegetable protein, g/day/kg body weight & 0.73 & 0.44 & 0.21 & 2.9 & \\
\hline Fat, g/day & 48 & 29 & 10 & 151 & \\
\hline Fiber, g/day & 30 & 17 & 6 & 125 & \\
\hline Calcium, mg/day & 1340 & 655 & 342 & 4105 & 1000 mg/day \\
\hline Vitamin C, mg/day & 274 & 182 & 47 & 934 & 75 mg/day \\
\hline Vitamin D, IU/day & 231 & 145 & 4.5 & 897 & 200 IU/day \\
\hline Phosphorous, mg/day & 389 & 206 & 36 & 1142 & 700 mg/day \\
\hline Potassium, mg/day & 1689 & 897 & 142 & 5054 & 4700 mg/day \\
\hline Iron, mg/day & 21.9 & 10.8 & 6.4 & 62.7 & 18 mg/day \\
\hline Dairy, servings/day & 2.9 & 1.8 & 0 & 9.9 & \\
\hline Fruits and vegetables, servings/day & 5.4 & 4.2 & 0.3 & 21.0 & \\
\hline \multicolumn{6}{|l|}{ Beverages } \\
\hline Sweetened soda, ounces/day & 1.4 & 3.4 & 0 & 30 & \\
\hline Diet soda, ounces/day & 4.2 & 10.3 & 0 & 54 & \\
\hline Coffee, ounces/day & 6.4 & 12.2 & 0 & 72 & \\
\hline Caffeine, mg/day & 140 & 234 & 0 & 1350 & \\
\hline Skim milk, ounces/day & 5.7 & 8.5 & 0 & 56 & \\
\hline Total dairy milk, ounces/day & 7.6 & 8.7 & 0 & 56 & \\
\hline Total alcohol, standard drinks/day & 0.3 & 0.4 & 0 & 2.6 & \\
\hline
\end{tabular}

dairy, lower consumption of fat; pattern 2: higher fruits and vegetable consumption, higher fiber and lower fat consumption; pattern 3: higher animal protein, higher fat, lower fruits and vegetable, lower fiber consumption; and pattern 4: higher protein (both animal and vegetable). Using these 4 patterns, we found that individuals with a high dairy and low fat intake (pattern 1 ) had a significantly reduced risk of a stress fracture (Table 3$)(P<.05)$.

There were no significant interactions between stress fracture risk and nutrition with either treatment assignment or menstrual status (each $P>.05$, data not shown).

\section{Nutrients and Annual Change in BMD}

Individual nutrients were assessed in relation to change in BMD; the results are presented in Table 4a. Calcium intake was positively related to annual gains in BMD of the hip $(P<$ $.05)$ and total body $(P<.005)$, as well as total body BMC $(P<.005)$. For every standard deviation increase in calcium intake (approximately $600 \mathrm{mg}$ ), women gained an additional $0.0016 \mathrm{~g} / \mathrm{cm}^{2}$ (an average $0.16 \%$ gain) in spine BMD annually $(P=.07), 0.0022 \mathrm{~g} / \mathrm{cm}^{2}$ (an average $0.26 \%$ gain) in hip BMD, $0.0025 \mathrm{~g} / \mathrm{cm}^{2}$ (an average $0.23 \%$ gain) in total body $\mathrm{BMD}$, and $6.6 \mathrm{~g}$ (an average $0.30 \%$ gain) in total body BMC. Skim milk, total milk intake, and number of dairy servings per day also predicted significant gains in hip BMD and whole-body BMC; vitamin D intake predicted gains in spine and hip BMD; and animal protein, a component of milk, predicted gains in whole-body BMD and BMC. There was a positive relationship between increased intake of potassium and significant increases in BMD of the hip and whole body and whole-body BMC. For every standard deviation increase in potassium (approximately $900 \mathrm{mg}$ ), there was a gain of $6 \pm 2.3$ grams per year in total body BMC. Coffee intake also predicted positive changes in spine $(P<.05)$ and hip BMD $(P<.01)$ (Table 4a).

Using the 4 dietary patterns that resulted from the reduced rank regression analysis, we found that individuals with diets high in dairy and low in fat had a greater annual increase in hip BMD $(P<.05)$, and individuals with diets high in fruits, vegetables, and fiber and low in fat consumption had significantly greater increases in whole-body BMD and BMC $(P<.005$ and $P<.01$, respectively $)$.

All data were stratified by menstrual regularity versus irregularity to evaluate the joint effects of menstrual function and diet (Table $4 \mathrm{~b})$. Consumption of dairy products predicted positive change in hip BMD in both menstrual groups. Calcium intake predicted significant positive bone changes in women with both regular and irregular menstrual function, although the magnitudes of the changes were higher in the irregularly menstruating women. The positive effect of animal protein on total body bone was confined to irregularly menstruating women; no effect was found in regularly menstruating women. Last, the effects of fruits and vegetables as well as potassium varied by menstrual status and skeletal site. There was no clear pattern of effect (positive or negative) across skeletal sites.

To evaluate whether the positive effect of certain nutrients are independent of calcium intake, several analyses were repeated, controlling for calcium intake. Controlling for calcium intake attenuated, by approximately $25 \%$, the effects of 
Table 3. Adjusted ${ }^{*}$ hazard ratios (and $95 \%$ confidence interval) for associations between nutrients and stress fractures $(n=125)$

\begin{tabular}{|c|c|}
\hline Nutrient & $\begin{array}{c}\text { Hazard Ratio } \\
\text { (95\% Cl) }\end{array}$ \\
\hline $\begin{array}{l}\text { Kilocalories, per } 1 \text { standard } \\
\text { deviation (913 kcal) }\end{array}$ & $0.63(0.34-1.15)$ \\
\hline $\begin{array}{l}\text { Animal protein, g/day/kg } \\
\text { body weight }\end{array}$ & $0.42(0.15-1.20)$ \\
\hline $\begin{array}{l}\text { Vegetable protein, g/day/kg } \\
\text { body weight }\end{array}$ & $0.57(0.11-2.91)$ \\
\hline $\begin{array}{l}\text { Fat, per } 1 \text { standard deviation } \\
\text { (29 grams/day) }\end{array}$ & $1.02(0.58-1.70)$ \\
\hline $\begin{array}{l}\text { Fiber, per } 1 \text { standard deviation } \\
\text { (17 grams/day) }\end{array}$ & $1.11(0.49-2.52)$ \\
\hline $\begin{array}{l}\text { Calcium, per } 1 \text { standard } \\
\text { deviation }(655 \mathrm{mg})\end{array}$ & $0.53(0.29-0.97)^{\dagger}$ \\
\hline $\begin{array}{l}\text { Vitamin C, per } 1 \text { standard } \\
\text { deviation (182 mg) }\end{array}$ & $1.26(0.69-2.30)$ \\
\hline $\begin{array}{l}\text { Vitamin } D \text {, per } 1 \text { standard } \\
\text { deviation (145 IU) }\end{array}$ & $0.67(0.34-1.31)$ \\
\hline $\begin{array}{l}\text { Phosphorous, per } 1 \text { standard } \\
\text { deviation (206 mg) }\end{array}$ & $1.00(0.51-1.96)$ \\
\hline $\begin{array}{l}\text { Potassium 1, per } 1 \text { standard } \\
\text { deviation (897 mg) }\end{array}$ & $0.76(0.39-1.47)$ \\
\hline $\begin{array}{l}\text { Iron, per } 1 \text { standard deviation } \\
\quad(11 \mathrm{mg})\end{array}$ & $1.43(0.82-2.49)$ \\
\hline $\begin{array}{l}\text { Fruits and vegetables, per } \\
\text { serving }\end{array}$ & $0.89(0.74-1.07)$ \\
\hline Dairy products, per serving & $0.60(0.40-0.89)^{\dagger}$ \\
\hline Skim milk, cups/day & $0.38(0.16-0.90)^{\dagger}$ \\
\hline Total milk, cups/day & $0.43(0.20-0.89)^{\dagger}$ \\
\hline Coffee, cups/day & $0.94(0.63-1.40)$ \\
\hline Dietary pattern 1 & $0.32(0.10-0.96)^{\dagger}$ \\
\hline Dietary pattern 2 & $0.63(0.32-1.24)$ \\
\hline Dietary pattern 3 & $1.06(0.54-2.09)$ \\
\hline Dietary pattern 4 & $1.54(0.31-7.48)$ \\
\hline
\end{tabular}

${ }^{*}$ Cox proportional hazards models were used to evaluate the relationship of baseline nutrient intake, beverage consumption. and dietary patterns with stress fracture incidence adjusted for clinical site, treatment group assignment, baseline menstrual status, spine bone density, age, and stress fracture history.

${ }^{\dagger} P<.05$.

Dietary pattern $1=$ high dairy, low fat; dietary pattern $2=$ high fruits and vegetable, high fiber, low fat; dietary pattern $3=$ high animal protein, high fat, low fruits and vegetables, low fiber; dietary pattern $4=$ high protein (both animal and vegetable).

animal protein on gains in total body BMD/BMC, although the relationship remained significant. Controlling for calcium in the models relating potassium to gain in bone density slightly attenuated the effect at the hip and spine $(\sim 10 \%$ attenuation), with a somewhat greater attenuation for the relationship at the total body $(\sim 20 \%)$, although statistical significance was not changed. Adjustment for calcium intake had no impact on the estimates of the effect of coffee on spine and hip BMD; however, the food frequency questionnaire did not specifically ask participants about the consumption of coffee beverages containing milk (such as lattes).

\section{DISCUSSION}

In this study of young female runners, skim milk intake and total dairy product intake were associated with protection against stress fracture. Consistent with this finding, an evaluation of dietary patterns (an analysis that allows simultaneous evaluation of correlated dietary factors) showed that runners with a high dairy product intake along with a low-fat diet had a significantly reduced risk of stress fracture. Small longitudinal increases in BMD at each skeletal site were positively related to specific dietary intakes. Annual increases in hip BMD were related to higher intakes of calcium, vitamin $\mathrm{D}$, potassium, coffee, milk, and dairy products; annual increases in spine BMD were related to higher intakes of vitamin D and coffee; and annual increases in whole-body BMD and BMC were related to higher intakes of animal protein, calcium, potassium, milk, and dairy products. We also identified 2 different dietary patterns that were related to skeletal mass. A diet high in dairy intake and low in fat intake was associated with gains in hip BMD, and a diet high in fruits, vegetables, and fiber intake and low in dietary fat was associated with gains in total body BMD and BMC. No single nutrient is eaten in isolation; therefore, it is important to use analysis techniques, such as reduced rank regression, to evaluate the interrelationships of dietary variables.

We previously reported that low bone mass and low BMD were associated with an increased risk for stress fracture [56], a finding that is consistent with other prospective studies carried out in competitive athletes [1,3] and military recruits [7]. Therefore, it is not surprising that many of the same nutrients and foods (dairy products, calcium, vitamin D, and milk) found to be protective against stress fractures were also related to increases in BMD.

Our study is the first prospective study to demonstrate protective effects of calcium and vitamin D on stress fracture risk in female athletes. Each additional cup of skim milk consumed per day was associated with a $62 \%$ decrease in stress fracture incidence. Thus, increasing dairy consumption may represent a relatively simple intervention that women runners can implement to substantially reduce their fracture risk. Though a previous case-control study reported a relationship between low calcium and dairy consumption and increased risk of stress fracture in female athletes [5], other studies in female athletes and military recruits have found no association [3-7]. In the only other prospective study to examine this relationship in female athletes [3], women with fractures actually had a higher, though not significant, calcium intake than women with no fractures. However, calcium was measured in the middle and at the end of the study, and women with fractures may have increased their calcium intake in response to their fractures. Our findings are supported by a recent report [8] in female Navy recruits; in that trial, women randomized to supplementation with $2000 \mathrm{mg}$ calcium and 800 international units of vitamin 
Table 4a. Adjusted* annual rates of change in spine, hip, and whole-body mineral density (BMD) and whole-body bone mineral content (BMC) and skeletal area by nutrients and dietary patterns

\begin{tabular}{|c|c|c|c|c|}
\hline Nutrient (SD) & $\begin{array}{c}\text { Spine BMD } \\
\left(\mathrm{g} / \mathrm{cm}^{2} / \text { year } \pm \text { SE) }\right.\end{array}$ & $\begin{array}{c}\text { Total Hip BMD } \\
\left(\mathrm{g} / \mathrm{cm}^{2} / \text { year } \pm \text { SE }\right)\end{array}$ & $\begin{array}{l}\text { Whole-body BMD } \\
\left(\mathrm{g} / \mathrm{cm}^{2} / \text { year } \pm \mathrm{SE}\right)\end{array}$ & $\begin{array}{c}\text { Whole-body BMC } \\
\text { (g/year } \pm \text { SE) }\end{array}$ \\
\hline $\begin{array}{l}\text { Animal protein, g/day/kg body } \\
\text { weight }\end{array}$ & $0.00150 \pm 0.00229$ & $0.00350 \pm 0.00216$ & $0.00602 \pm 0.00219^{\dagger}$ & $16.4 \pm 5.1^{\ddagger}$ \\
\hline $\begin{array}{l}\text { Vegetable protein, g/day/kg } \\
\text { body weight }\end{array}$ & $-0.00284 \pm 0.00210$ & $0.00093 \pm 0.00200$ & $-0.00308 \pm 0.00205$ & $3.6 \pm 4.8$ \\
\hline Fat, per 1 SD (29g) & $-0.00068 \pm 0.00098$ & $-0.00026 \pm 0.00093$ & $0.000376 \pm 0.00096$ & $-0.8 \pm 2.3$ \\
\hline Fiber, per 1 SD (17 g) & $0.00057 \pm 0.00079$ & $0.00012 \pm 0.00075$ & $-0.00119 \pm 0.00077$ & $0.7 \pm 1.8$ \\
\hline Calcium, per 1 SD (655 mg) & $0.00160 \pm 0.00089$ & $0.00216 \pm 0.00083^{*}$ & $0.0025 \pm 0.00085^{\ddagger}$ & $6.6 \pm 2.0^{\ddagger}$ \\
\hline Vitamin C, per 1 SD (182 mg) & $0.00084 \pm 0.00104$ & $-0.00009 \pm 0.00098$ & $0.00108 \pm 0.00101$ & $1.9 \pm 2.4$ \\
\hline Vitamin D, per 1 SD (145 IU) & $0.00229 \pm .00100^{*}$ & $0.00251 \pm .00095^{\dagger}$ & $0.00136 \pm 0.00099$ & $4.0 \pm 2.3$ \\
\hline Phosphorous, per 1 SD (206 mg) & $0.00143 \pm 0.00107$ & $0.00063 \pm 0.00102$ & $0.00234 \pm 0.00104^{*}$ & $3.9 \pm 2.4$ \\
\hline Potassium, per 1 SD (897 mg) & $0.00198 \pm 0.00102$ & $0.00236 \pm 0.00095^{\star}$ & $0.00259 \pm 0.001^{*}$ & $6.0 \pm 2.3^{*}$ \\
\hline Iron, per 1 SD (10.8 mg) & $0.00139 \pm 0.00101$ & $0.00108 \pm 0.00096$ & $-0.00185 \pm 0.00098$ & $-1.6 \pm 2.3$ \\
\hline Fruits and vegetables, per serving & $-0.00012 \pm 0.00025$ & $-.00004 \pm 0.00024$ & $.00030 \pm 0.00024$ & $1.1 \pm 0.6$ \\
\hline Dairy, per serving & $0.00069 \pm 0.00058$ & $.00127 \pm 0.00054^{*}$ & $.00129 \pm 0.00056^{*}$ & $4.1 \pm 1.3^{\ddagger}$ \\
\hline Skim milk, per additional cup/day & $0.00095 \pm .00096$ & $.00258 \pm .00089^{\ddagger}$ & $.00132 \pm .00094$ & $5.2 \pm 2.2^{*}$ \\
\hline $\begin{array}{l}\text { Total milk, per additional cup/ } \\
\text { day }\end{array}$ & $0.00063 \pm .00093$ & $.00262 \pm .00086^{\ddagger}$ & $.00103 \pm 0.00092$ & $5.1 \pm 2.1^{*}$ \\
\hline Coffee, per additional cup /day & $0.00148 \pm .00067^{*}$ & $.00170 \pm .00063^{\dagger}$ & $.00099 \pm 0.00067$ & $-0.4 \pm 1.5$ \\
\hline Dietary pattern 1 & $0.00179 \pm 0.00137$ & $.00280 \pm 0.0013$ & $.00091 \pm 0.00135$ & $4.9 \pm 3.2$ \\
\hline Dietary pattern 2 & $0.00125 \pm 0.00118$ & $.00036 \pm 0.00113$ & $.00369 \pm 0.00113^{\ddagger}$ & $7.3 \pm 2.7^{\dagger}$ \\
\hline Dietary pattern 3 & $-0.00080 \pm 0.00108$ & $-.00028 \pm 0.00103$ & $-.00237 \pm 0.00104^{*}$ & $-1.4 \pm 2.5$ \\
\hline Dietary pattern 4 & $0.00302 \pm 0.00192$ & $.00211 \pm 0.00184$ & $-.00362 \pm 0.00189$ & $2.4 \pm 4.5$ \\
\hline
\end{tabular}

Dietary pattern 1 = high dairy, low fat; dietary pattern 2 = high fruits and vegetables, high fiber, low fat; dietary pattern $3=$ high animal protein, high fat, low fruits and vegetables, low fiber; dietary pattern $4=$ high protein (both animal and vegetable).

Baseline nutrient intake for calcium, vitamin C, vitamin D, phosphorous, potassium, iron, fiber, and fat is adjusted for caloric intake using the residual [54] Units for dairy, fruits, and vegetables are servings per day; units for animal and vegetable protein are grams per day per kilogram of body weight.

*Annual rates of change are estimated from linear mixed models, adjusted for clinical site, age, annual menses, and treatment assignment in the randomized trial. Dietary patterns were derived from a Reduced Rank Regression method. Am J Epidemiol 2004; 159:935-944.

$* P<.05$, rate of change differs from 0 .

${ }^{\dagger} P<.01$, rate of change differs from 0 .

${ }^{\ddagger} P<.005$, rate of change differs from 0 .

D versus placebo for 8 weeks of basic training had a 20\% lower incidence of stress fracture.

We found that dairy products and calcium protected against stress fractures even after controlling for bone density. That the stress fracture protection is independent of BMD suggests that other aspects of bone strength are involved. For instance, in one study, lower milk intake was related to a smaller cortical thickness [39], and, conversely, cheese supplementation (in children) increased cortical thickness [40]. This effect of dairy on skeletal geometry may relate to differences in risk for stress fractures.

One previous study reported that a low-fat diet was a risk factor for stress fracture [3], rather than a protective factor as we found here. However, recent analyses of National Health and Nutrition Examination Survey (NHANES) data indicate that higher intakes of saturated fat are related to lower BMD [57], perhaps consistent with our findings, although we did control for baseline BMD in the analysis. It is also possible that the protective effect of the low-fat diet against stress fracture is only when combined with higher intakes of dairy foods, as indicated by the dietary patterns analysis.

Our findings that dairy products and skim milk were related to a modest increase in BMD are similar to other studies reporting that low intakes of calcium and dairy products have been associated with decreased BMD in young adult women [58]. However, this is the first prospective study to show this relationship in young female athletes. There may be overlap in some of these variables in that $75 \%$ of milk intake was reported as skim milk consumption and $25 \%$ of servings of dairy per day were from skim milk.

The finding of coffee intake having a positive relationship with spine and hip BMD could be due to chance or could reflect the addition of dairy products to coffee. High coffee intake has sometimes been linked to lower bone mass in the setting of very low calcium intake [46]. Our study suggests that coffee intake, at the moderate levels consumed in this study (an average intake of 1 cup per day), has no adverse effect on bone health in female runners, and may even be beneficial if milk-based coffee drinks, such as lattes, are consumed. Thus, women runners should not be advised to reduce their coffee intake to improve skeletal health. There was no effect of alcohol or soda on stress fracture occurrence or change in $\mathrm{BMD}$, perhaps because of the small number of women who consumed these products. In addition, the lack of a specific cola category [59] may have limited the ability to 
Table 4b. Adjusted* annual rates of change in spine, hip, and whole body mineral density (BMD) and whole body bone mineral content (BMC) and skeletal area by nutrients by regularity ${ }^{\dagger}$ of current menstrual cycles

\begin{tabular}{|c|c|c|c|c|}
\hline Nutrient & $\begin{array}{c}\text { Spine BMD } \\
\left(\mathrm{g} / \mathrm{cm}^{2} / \text { year } \pm \text { SE }\right)\end{array}$ & $\begin{array}{c}\text { Total Hip BMD } \\
\left(\mathrm{g} / \mathrm{cm}^{2} / \text { year } \pm \mathrm{SE}\right)\end{array}$ & $\begin{array}{l}\text { Whole-body BMD } \\
\left(\mathrm{g} / \mathrm{cm}^{2} / \text { year } \pm \text { SE) }\right.\end{array}$ & $\begin{array}{l}\text { Whole-body BMC } \\
\text { (kg/year } \pm \text { SE) }\end{array}$ \\
\hline \multicolumn{5}{|l|}{ Dairy, per serving } \\
\hline Regular & $0.00016 \pm 0.00067$ & $0.00155 \pm 0.00065^{\ddagger}$ & $0.00047 \pm 0.00076$ & $0.8 \pm 1.56$ \\
\hline Irregular & $0.00177 \pm 0.00116$ & $0.00134 \pm 0.00098$ & $0.00221 \pm 0.00101^{\ddagger}$ & $7.5 \pm 3.1^{\ddagger}$ \\
\hline Calcium, per 1 SD (655 mg) & & $0.00181 \pm 0.00102$ & $0.00227 \pm 0.00118$ & $3.2 \pm 2.42$ \\
\hline Regular & $0.00146 \pm 0.00104$ & $0.00316 \pm 0.00155^{\ddagger}$ & $0.00434 \pm 0.00159 \$$ & $13.4 \pm 5.12^{\ddagger}$ \\
\hline Irregular & $0.00240 \pm 0.00187$ & & & \\
\hline \multicolumn{5}{|l|}{ Total milk, per cup } \\
\hline Regular & $-0.00024 \pm 0.00108$ & $0.00228 \pm 0.00097^{\ddagger}$ & $0.00071 \pm 0.00116$ & $1.7 \pm 2.3$ \\
\hline Irregular & $0.00285 \pm 0.00195$ & $0.00359 \pm 0.00174^{\ddagger}$ & $0.00083 \pm 0.00176$ & $9.2 \pm 5.2$ \\
\hline \multicolumn{5}{|c|}{ Fruits and vegetables, per serving } \\
\hline Regular & $-0.00068 \pm 0.00028^{\ddagger}$ & $-0.00044 \pm 0.00028$ & $0.00013 \pm 0.00033$ & $-0.1 \pm 0.7$ \\
\hline Irregular & $0.00069 \pm 0.00046$ & $0.00084 \pm 0.00038^{\ddagger}$ & $0.00058 \pm 0.00041$ & $3.1 \pm 1.2^{\ddagger}$ \\
\hline \multicolumn{5}{|l|}{ Potassium, per 1 SD (897 mg) } \\
\hline Regular & $0.00167 \pm 0.00128$ & $0.00192 \pm 0.00124$ & $0.00405 \pm 0.00145^{\S}$ & $5.4 \pm 3.0$ \\
\hline Irregular & $0.00194 \pm 0.00165$ & $0.00285 \pm 0.00136^{\ddagger}$ & $0.00164 \pm 0.00146$ & $7.5 \pm 4.3$ \\
\hline \multicolumn{5}{|c|}{$\begin{array}{l}\text { Animal protein, g/day/kg body } \\
\text { weight }\end{array}$} \\
\hline Regular & $-0.00177 \pm 0.00263$ & $0.00305 \pm 0.00258$ & $-0.00060 \pm 0.00299$ & $-4.1 \pm 6.1$ \\
\hline Irregular & $0.00663 \pm 0.00384$ & $0.00518 \pm 0.00326$ & $0.00795 \pm 0.00334^{\ddagger}$ & $26.9 \pm 9.8^{\S}$ \\
\hline
\end{tabular}

Baseline nutrient intake for calcium and potassium is adjusted for caloric intake using the residual method [54].

Units for dairy, fruits, and vegetables are servings per day; units for animal protein are grams per day per kilogram of body weight.

*Annual rates of change are estimated from linear mixed models, adjusted for clinical site, age, and treatment assignment in the randomized trial.

'Women were classified as having current menstrual irregularity if they were oligomenorrheic (defined as 4-9 cycles in the past year) or amenorrheic (defined as fewer than 4 cycles in the past year).

${ }^{\ddagger} P<.05$, rate of change differs from 0 .

${ }^{\S} P<.01$, rate of change differs from 0 .

find any association between these skeletal outcomes and soda, if such an association exists.

Protein intake, specifically animal protein, was related to small but significantly greater increases in total body bone mass. Similar results have been reported in women of a similar age $[26,60,61]$, but this is the first prospective study to show this relationship in young women athletes. One possible mechanism is that protein may alter the response to calcium supplementation $[62,63]$, possibly through improving calcium absorption [64]. Or, protein-related changes may increase concentrations of insulin-like growth factor-1 (IGF-1) that may have a positive skeletal benefit [64]. In general, diets that are moderate in protein intake (1-1.5 g protein/kg body weight), such as those reported in this study, are associated with normal calcium metabolism, whereas diets high in protein have been reported to cause excessive urinary calcium excretion (64) or may create an acidic environment that favors bone resorption [65]. That a positive change in whole-body BMD/BMC was related to animal protein may also be a reflection of the animal protein found in dairy intake, a dietary component that was positively related to BMD change. In fact, $47 \%$ of the grams of animal protein per day came from dairy consumption, and the estimate of the effect of animal protein was partially reduced after controlling for calcium.
In our study, a high potassium intake was associated with greater gains in hip BMD and total body BMD/BMC (independent of the effect of calcium); and a high fruit and vegetable intake was associated with greater gains in total body BMD/BMC. Several cross-sectional studies have reported that potassium, magnesium, and vitamin $C$ intakes are related to higher BMD $[32,66,67]$. Longitudinal studies have also found a correlation between potassium, magnesium and vitamin C intakes [57] or fruit and vegetable intakes [45] and change in BMD in non-athlete populations. Potassium and magnesium may reduce bone turnover [66] and may contribute to the alkali load, serving as a buffer to the acid load of a diet $[49,68,69]$. In addition, fruits and vegetables may promote bone health through action of other nutrients such as vitamin K $[32,66,67,70-73]$. Clearly, our finding of higher potassium intake relating to hip and total body BMD needs to be further explored. However, the finding is strengthened by a consistent beneficial effect of potassium across skeletal sites and because the dietary pattern relating to positive BMD changes included fruits and vegetables, a major source of potassium.

Several previous studies in competitive athletes and military recruits have reported that current or past menstrual irregularity is associated with an increased risk for stress fracture and greater bone loss [1,3-5,74,75]. Menstrual irreg- 
ularity could also potentially modify the effect of risk factors; therefore, we have controlled for this variable in the analyses and also stratified on this variable. In women with irregular menses, intake of protein and calcium may be of greater importance for skeletal health than for runners with regular menses. Although we previously reported an association at baseline between disordered eating and low BMD among eumenorrheic runners [76], no association between disordered eating and subsequent stress fracture occurrence or bone loss was seen in our longitudinal analyses. However, our findings do indicate that nutritional intake may have a larger impact on changes in BMD and BMC in irregularly menstruating women who may have a backdrop of poor nutrition and may also have eating disorders.

Our prospective study had the advantage of collecting information on possible risk factors before the occurrence of the stress fractures and without knowledge of BMD, thus eliminating the possibility of biased recall. In addition, all participants were from one sport, cross-country running, thus eliminating sport as a potential source of variation in both stress fracture occurrence and longitudinal changes in BMD. One limitation is that our study population was of modest size, with only 17 new stress fractures; also, the small expected changes in BMD would make it difficult to find dietary determinants of change. Another limitation was the lack of follow-up information on $17 \%$ of the original participants, related to the high degree of mobility in women of this age. Finally, there is the possibility of uncontrolled or unmeasured confounding. In particular, it is difficult to separate the effects of dietary constituents that tend to be consumed together. However, the dietary pattern analysis allows the simultaneous evaluation of correlated dietary constituents. Measurement error in diet assessment is also likely to have occurred.

\section{CONCLUSION}

In conclusion, the results of our study indicate that in young female runners' dairy product intake, particularly low-fat milk, and the major nutrient components of milk (calcium, vitamin $\mathrm{D}$, and protein) are related to greater bone gains and lower stress fracture risk. Potassium intake, related to fruit and vegetable intake, was also associated with greater gains in hip and total body BMD. Therefore, an overall healthy diet, with low-fat milk to provide adequate calcium and vitamin D and sufficient in fruits and vegetables, may provide the greatest skeletal benefit to cross-county runners.

\section{REFERENCES}

1. Nattiv A. Stress fractures and bone health in track and field athletes. J Sci Med Sport 2000;3:268-279.

2. Bennell KL, Malcolm SA, Thomas SA, Wark JD, Brukner PD. The incidence and distribution of stress fractures in competitive track and field athletes. A twelve-month prospective study. Am J Sports Med 1996;24:211-217.

3. Bennell KL, Malcolm SA, Thomas SA, et al. Risk factors for stress fractures in track and field athletes. A twelve-month prospective study. Am J Sports Med 1996;24:810-818.

4. Bennell KL, Malcolm SA, Thomas SA, et al. Risk factors for stress fractures in female track-and-field athletes: A retrospective analysis. Clin J Sport Med 1995;5:229-235.

5. Myburgh KH, Hutchins J, Fataar AB, Hough SF, Noakes TD. Low bone density is an etiologic factor for stress fractures in athletes. Ann Intern Med 1990;113:754-759.

6. Cline AD, Jansen GR, Melby CL. Stress fractures in female army recruits: Implications of bone density, calcium intake, and exercise. J Am Coll Nutr 1998;17:128-135.

7. Lappe JM, Stegman MR, Recker RR. The impact of lifestyle factors on stress fractures in female Army recruits. Osteoporos Int 2001;12:35-42.

8. Lappe J, Cullen D, Haynatzki G, Recker R, Ahlf R, Thompson K Calcium and vitamin D supplementation decreases incidence of stress fractures in female navy recruits. J Bone Miner Res 2008;23:741-749.

9. Nattiv A, Loucks AB, Manore MM, Sanborn CF, Sundgot-Borgen J, Warren MP. American College of Sports Medicine position stand. The female athlete triad. Med Sci Sports Exerc 2007;39:1867-1882.

10. Hernandez CJ, Beaupre GS, Carter DR. A theoretical analysis of the relative influences of peak BMD, age-related bone loss and menopause on the development of osteoporosis. Osteoporos Int 2003;14:843-847.

11. Lloyd $T$, Buchanan JR, Bitzer $S$, et al. Interrelationships of diet, athletic activity, menstrual status, and bone density in collegiate women. Am J Clin Nutr 1987;46:681-684

12. Kirchner EM, Lewis RD, O'Connor PJ. Bone mineral density and dietary intake of female college gymnasts. Med Sci Sports Exerc 1995;27:543549.

13. Wolman RL, Clark P, McNally E, et al. Dietary calcium as a statistical determinant of spinal trabecular BMD in amenorrhoeic and oestrogenreplete athletes. Bone Miner 1992;17:415-423.

14. Winzenberg TM, Shaw K, Fryer J, Jones G. Calcium supplementation for improving bone mineral density in children. Cochrane Database Syst Rev 2006:CD005119.

15. Cranney A, Horsley T, O'Donnell S, et al. Effectiveness and safety of vitamin D in relation to bone health. Evid Rep Technol Assess (Full Rep) 2007;Aug:1 235

16. Specker B, Vukovich M. Evidence for an interaction between exercise and nutrition for improved bone health during growth. Med Sport Sci 2007:51:50-63.

17. Hoppe $C$, Molgaard $C$, Michaelsen KF. Bone size and bone mass in 10-year-old Danish children: effect of current diet. Osteoporos Int 2000;11:1024-1030

18. Bounds W, Skinner J, Carruth BR, Ziegler P. The relationship of dietary and lifestyle factors to bone mineral indexes in children. J Am Diet Assoc 2005; 105:735-741.

19. Alexy U, Remer T, Manz F, Neu CM, Schoenau E. Long-term protein intake and dietary potential renal acid load are associated with bone modeling and remodeling at the proximal radius in healthy children. Am J Clin Nutr 2005;82:1107-1114.

20. Patterson BM, Cornell CN, Carbone B, Levine B, Chapman D. Protein depletion and metabolic stress in elderly patients who have a fracture of the hip. J Bone Joint Surg Am 1992;74:251-260.

21. Garn SM, Guzman MA, Wagner B. Subperiosteal gain and endosteal loss in protein-calorie malnutrition. Am J Phys Anthropol 1969;30: 153-155

22. Parfitt AM. Dietary risk factors for age-related bone loss and fractures Lancet 1983:2:1181-1185.

23. Rizzoli R, Ammann $P$, Chevalley $T$, Bonjour JP. Protein intake and bone disorders in the elderly. Joint Bone Spine 2001;68:383-392.

24. Schaafsma G, van Beresteyn EC, Raymakers JA, Duursma SA. Nutritional aspects of osteoporosis. World Rev Nutr Diet 1987;49:121-159. 
25. Geinoz G, Rapin $\mathrm{CH}$, Rizzoli R, et al. Relationship between bone mineral density and dietary intakes in the elderly. Osteoporos Int 1993;3:242-248.

26. Teegarden D, Lyle RM, McCabe GP, et al. Dietary calcium, protein, and phosphorus are related to bone mineral density and content in young women. Am J Clin Nutr 1998;68:749-754.

27. Prynne CJ, Mishra GD, O'Connell MA, et al. Fruit and vegetable intakes and bone mineral status: A cross sectional study in 5 age and sex cohorts. Am J Clin Nutr 2006;83:1420-1428.

28. New SA, Millward DJ. Calcium, protein, and fruit and vegetables as dietary determinants of bone health. Am J Clin Nutr 2003;77:13401341; author reply 1341.

29. Lanham-New SA. Fruit and vegetables: The unexpected natural answer to the question of osteoporosis prevention? Am J Clin Nutr 2006;83: 1254-1255.

30. DeBar LL, Ritenbaugh C, Aickin M, et al. Youth: A health plan-based lifestyle intervention increases bone mineral density in adolescent girls. Arch Pediatr Adolesc Med 2006;160:1269-1276.

31. Sugiura M, Nakamura $M$, Ogawa $K$, Ikoma $Y$, Ando F, Yano M. Bone mineral density in post-menopausal female subjects is associated with serum antioxidant carotenoids. Osteoporos Int 2008;19:211-219.

32. New $S A$, Bolton-Smith $C$, Grubb DA, Reid DM. Nutritional influences on bone mineral density: A cross-sectional study in premenopausal women. Am J Clin Nutr 1997;65:1831-1839.

33. Nieves JW, Golden AL, Siris E, Kelsey JL, Lindsay R. Teenage and current calcium intake are related to bone mineral density of the hip and forearm in women aged 30-39 years. Am J Epidemiol 1995;141: 342-351.

34. D'Amelio P, Cristofaro MA, Tamone $\mathrm{C}$, et al. Role of iron metabolism and oxidative damage in postmenopausal bone loss. Bone 2008;43: 1010-1015.

35. Abraham R, Walton J, Russell L, et al. Dietary determinants of postmenopausal bone loss at the lumbar spine: A possible beneficial effect of iron. Osteoporos Int 2006;17:1165-1173.

36. Merrilees MJ, Smart EJ, Gilchrist NL, et al. Effects of diary food supplements on bone mineral density in teenage girls. Eur J Nutr 2000;39:256-262.

37. Lanou AJ, Berkow SE, Barnard ND. Calcium, dairy products, and bone health in children and young adults: a reevaluation of the evidence. Pediatrics 2005;115:736-743.

38. Storey ML, Forshee RA, Anderson PA. Associations of adequate intake of calcium with diet, beverage consumption, and demographic characteristics among children and adolescents. J Am Coll Nutr 2004;23:1833.

39. Ruffing J, Cosman F, Zion M, et al. Determinants of bone mass and bone size in a large cohort of physically active young adult men. Nutr Metab (Lond) 2006:3:14

40. Cheng S, Lyytikainen A, Kroger $H$, et al. Effects of calcium, dairy product, and vitamin D supplementation on bone mass accrual and body composition in 10-12-y-old girls: A 2-y randomized trial. Am J Clin Nutr 2005;82:1115-1126; quiz 47-48.

41. Ma D, Jones G. Soft drink and milk consumption, physical activity, bone mass, and upper limb fractures in children: A population-based case-control study. Calcif Tissue Int 2004;75:286-291.

42. Wyshak G. Teenaged girls, carbonated beverage consumption, and bone fractures. Arch Pediatr Adolesc Med 2000;154:610-613

43. Chakkalakal DA. Alcohol-induced bone loss and deficient bone repair. Alcohol Clin Exp Res 2005;29:2077-2090.

44. Nieves J. Nonskeletal risk factors for osteoporosis and fractures. In: Marcus PM, Feldman D, Nelson D, Rosen CJ, eds. Osteoporosis. Burlington, MA: Academic Press; 2007, 889-909.

45. Massey LK. Caffeine and the elderly. Drugs Aging 1998;13:43-50.

46. Nawrot P, Jordan S, Eastwood J, Rotstein J, Hugenholtz A, Feeley M. Effects of caffeine on human health. Food Addit Contam 2003;20:1-30.
47. Zanker $C$, Hind $K$. The effect of energy balance on endocrine function and bone health in youth. Med Sport Sci 2007;51:81-101.

48. Ihle R, Loucks AB. Dose-response relationships between energy availability and bone turnover in young exercising women. J Bone Miner Res 2004;19:1231-1240.

49. Prynne CJ, Ginty F, Paul AA, et al. Dietary acid-base balance and intake of bone-related nutrients in Cambridge teenagers. Eur J Clin Nutr 2004;58:1462-1471

50. Neville CE, Robson PJ, Murray LJ, et al. The effect of nutrient intake on bone mineral status in young adults: The Northern Ireland young hearts project. Calcif Tissue Int 2002;70:89-98.

51. Heaney RP. Nutrients, interactions and foods: the important of source. In: Burckhardt P, Dawson-Hughes B, Heaney RP, eds. Nutritional aspects of osteoporosis. San Diego, CA: Elsevier Science; 2004, 61-78.

52. Cobb KL, Bachrach LK, Sowers $M$, et al. The effect of oral contraceptives on bone mass and stress fractures in female runners. Med Sci Sports Exerc 2007;39:1464-1473.

53. Block GL, Coyle R, Smucker R, Harlan MC. Health habits and history questionnaire: Diet history and other risk factors. Bethesda, MD: National Cancer Institute; 1989.

54. Willett W, Stampfer MJ. Total energy intake: implications for epidemiologic analyses. Am J Epidemiol 1986;124:17-27.

55. Hoffmann $\mathrm{K}$, Zyriax BC, Boeing $\mathrm{H}$, Windler E. A dietary pattern derived to explain biomarker variation is strongly associated with the risk of coronary artery disease. Am J Clin Nutr 2004;80:633-640.

56. Kelsey JL, Bachrach LK, Procter-Gray E, et al. Risk factors for stress fracture among young female cross-country runners. Med Sci Sports Exerc 2007;39:1457-1463.

57. Corwin RL, Hartman TJ, Maczuga SA, Graubard BI. Dietary saturated fat intake is inversely associated with bone density in humans: Analysis of NHANES III. J Nutr 2006;136:159-165.

58. Weinsier RL, Krumdieck CL. Dairy foods and bone health: Examination of the evidence. Am J Clin Nutr 2000;72:681-689.

59. Tucker KL, Morita K, Qiao N, Hannan MT, Cupples LA, Kiel DP. Colas, but not other carbonated beverages, are associated with low bone mineral density in older women: The Framingham Osteoporosis Study. Am J Clin Nutr 2006;84:936-942.

60. Cooper C, Atkinson EJ, Hensrud DD, et al. Dietary protein intake and bone mass in women. Calcif Tissue Int 1996;58:320-325.

61. Hirota T, Nara M, Ohguri M, Manago E, Hirota K. Effect of diet and lifestyle on bone mass in Asian young women. Am J Clin Nutr 1992; 55:1168-1173

62. Chevalley T, Bonjour JP, Ferrari S, Rizzoli R. High protein intake enhances the positive impact of physical activity on bone mineral content in pre-pubertal boys. J Bone Miner Res 2007 Sep 24; PMID: 17892378

63. Chevalley T, Ferrari S, Hans D, et al. Protein intake modulates the effect of calcium supplementation on bone mass gain in prepubertal boys. J Bone Miner Res 2002;17:S17-S23.

64. Kerstetter JE, O'Brien KO, Insogna KL. Low protein intake: The impact on calcium and bone homeostasis in humans. J Nutr 2003;133:855S861S.

65. Arnett TR, Dempster DW. Effect of $\mathrm{pH}$ on bone resorption by rat osteoclasts in vitro. Endocrinology 1986;119:119-124.

66. New SA, Robins SP, Campbell MK, et al. Dietary influences on bone mass and bone metabolism: Further evidence of a positive link between fruit and vegetable consumption and bone health? Am J Clin Nutr 2000;71:142-151.

67. Tucker KL, Hannan MT, Chen H, Cupples LA, Wilson PW, Kiel DP. Potassium, magnesium, and fruit and vegetable intakes are associated with greater bone mineral density in elderly men and women. Am J Clin Nutr 1999;69:727-736.

68. New SA. Do vegetarians have a normal bone mass? Osteoporos Int 2004;15:679-688. 
69. Buclin T, Cosma M, Appenzeller M, et al. Diet acids and alkalis influence calcium retention in bone. Osteoporos Int 2001;12:493-499.

70. Bugel S. Vitamin K and bone health. Proc Nutr Soc 2003;62:839843.

71. Kalkwarf HJ, Khoury JC, Bean J, Elliot JG. Vitamin K, bone turnover, and bone mass in girls. Am J Clin Nutr 2004;80:10751080.

72. Cashman KD. Vitamin $K$ status may be an important determinant of childhood bone health. Nutr Rev 2005;63:284-289.

73. Macdonald HM, New SA, Golden MH, Campbell MK, Reid DM. Nutritional associations with bone loss during the menopausal transition: evidence of a beneficial effect of calcium, alcohol, and fruit and vegetable nutrients and of a detrimental effect of fatty acids. Am J Clin Nutr 2004;79:155-165.
74. Barrow GW, Saha S. Menstrual irregularity and stress fractures in collegiate female distance runners. Am J Sports Med 1988;16:209-216.

75. Carbon R, Sambrook PN, Deakin V, et al. Bone density of elite female athletes with stress fractures. Med J Aust 1990;153:373-376.

76. Cobb KL, Bachrach LK, Greendale G, et al. Disordered eating, menstrual irregularity, and bone mineral density in female runners. Med Sci Sports Exerc 2003;35:711-719.

This CME activity is designated for 1.0 AMA PRA Category 1 Credit ${ }^{\mathrm{TM}}$ and can be completed online at me.aapmr.org. Log on to www.me.aapmr.org, go to Lifelong Learning (CME) and select Journal-based CME from the drop down menu. This activity is FREE to AAPMER members and $\$ 25$ for non-members. 